\title{
CURRÍCULOS E DESEJOS E CORPOS E... UMA MICROPOLÍTICA ATIVA COM OS COTIDIANOS DAS ESCOLAS PÚBLICAS EM TEMPOS FASCISTAS
}

\author{
CURRICULA AND DESIRES AND BODIES AND... ACTIVE MICROPOLITICS WITH PUBLIC \\ SCHOOL DAILY LIFE IN FACIST TIMES
}

https://orcid.org/0000-0001-8995-4932 Marina de Oliveira Delmondes ${ }^{\mathrm{A}}$

${ }^{\text {A }}$ Universidade Federal do Espírito Santo (UFES) e Prefeitura Municipal de Guarapari, Guarapari, ES, Brasil

Recebido em: 28 set. 2020 | Aceito em: 18 abr. 2020 Correspondência: Marina Delmondes (marinaodelmondes@hotmail.com)

\begin{abstract}
Resumo
Essa escrita é um dos desdobramentos teóricos da pesquisa de doutorado que tem pensado (DELEUZE; GUATTARI, 2010) as relações entre corpos, currículos e cotidianos escolares a partir do campo epistemológico da filosofia da diferença e do aporte metodológico das pesquisas com os cotidianos. Frente às maquinações capitalísticas que arregimentam os corpos a um dado desejo disciplinar, problematiza-se como os currículos praticados com os cotidianos das escolas podem fazer insurgir uma micropolítica ativa (ROLNIK, 2018) em tempos fascistas. Em diálogo com Deleuze e Guattari, Suely Rolnik, Carlos Eduardo Ferraço, Silvio Gallo, entre outros intercessores, pressupomos que essa insurgência dos corpos pode ser inventada a partir de uma arte da resistência.
\end{abstract}

Palavras-chave: Currículos; Corpos; Desejos; Cotidiano escolar; Filosofia da Diferença.

\begin{abstract}
This writing is one of the theoretical developments of doctoral research that has been thinking (DELEUZE; GUATTARI, 2010) the relationships between bodies, curricula and school daily life from the epistemological field of the philosophy of difference and the methodological contribution of researches on everyday life. Facing of capitalism machines that enlist bodies to a given disciplinary desire, this research problematizes how the curricula practiced with school daily life can raise active micropolitics (ROLNIK, 2018) in fascist times. Dialoguing with Deleuze and Guattari, Suely Rolnik, Carlos Eduardo Ferraço, Silvio Gallo, among other intercessors, we assume that this insurgency of bodies can be invented from an art of resistance.
\end{abstract}

Keywords: Curricula. Bodies. Desires. School daily life. Philosophy of Difference.

\section{Maquinações I: um desejo}

Escrever é maquinar com um corpo a beira do esgotamento e que não tolera mais as normatizações. É traçar linhas desejantes. É operar um corte e inventar processos que façam uma aliança com uma vida. Essa escrita traz um recorte teórico da pesquisa de Doutorado em Educação. Um entrelaçamento de corpos e currículos e desejos e micropolíticas e macropolíticas e escolas e corpo-sem-órgãos e uma produção de subjetividade e... 
Com os cotidianos escolares, objetivamos pensar a potência dos currículos para a tessitura de uma micropolítica ativa (ROLNIK, 2018) cujo desejo é criar a possibilidade de aflorar outros gérmens de mundo (ROLNIK, 2018) em tempos fascistas.

Assumimos o campo epistemológico da filosofia da diferença e o aporte metodológico das pesquisas com os cotidianos em nossos estudos. Sinalizamos também, o apreço pela perspectiva da produção da diferença no campo da Educação.

Frente a produção de corpos disciplinados e controlados pelos dispositivos da sociedade de controle (DELEUZE, 2013) e pela máquina capitalística (ROLNIK, 2018), suspeitamos que uma experimentação corpo-sem-órgãos (DELEUZE; GUATTARI, 2011) concernente às práticas curriculares pode criar, ou não, modos de resistência diante das macropolíticas que arregimentam os corpos. Assim, questionamos: Quais desejos têm agenciado os múltiplos fazeres-saberes curriculares?

Nessa perspectiva, estabelecemos uma conversação sobre currículos e corpos e desejos e... não em uma tentativa de darmos respostas precisas como faz o método cartesiano, mas na investida de dar pistas para uma artesania dos corpos em processo de resistência. Deste modo,

Nós nos dirigimos aos inconscientes que protestam. Buscamos aliados. Precisamos de aliado. E temos a impressão de que esses aliados já existem, que eles não esperaram por nós, que tem muita gente que está farta, que pensa, sente e trabalha em direções análogas: não é questão de moda, mas de um 'ar do tempo' mais profundo, em que pesquisas convergentes estão sendo realizadas em domínios muito diversos (DELEUZE, 2013, p. 34 - grifo do autor).

Assim sendo, inferimos que a proposta desse texto é criar alianças para pensar uma resistência ao fascismo que se expande na sociedade brasileira atual. Para isso, realizamos uma problematização a partir do campo educacional, de modo particular, a partir das relações entre currículos, corpos, desejos e cotidianos escolares.

\section{Maquinações II: currículos e corpos e desejos e cotidianos escolares e...}

A escrita deleuzo-guattariana transita pelos campos da filosofia e da psicologia adentrando nos territórios da esquizoanálise. Assim, também pode ser pensada a escrita de Suely Rolnik. Contudo, a presente escrita é convergente. Neste tempo de atmosferas tóxicas (ROLNIK, 2018), o nosso interesse é pelos encontros-acontecimentos tecidos com a educação e visa problematizar as produções curriculares com os cotidianos das escolas.

A crítica empreendida pode ser pensada, também, como da ordem da produção de subjetividades, corpos e desejos regidas pelo inconsciente colonial-capitalístico (ROLNIK, 2018) que move as ações cotidianas e o modo como se reage às maquinações que afetam os 
corpos praticantes das escolas. Imersa em um contexto político intolerável e tóxico questionamos: o que podem os currículos nas múltiplas maquinações desejantes que potencializam, ou não, uma vida.

$\mathrm{O}$ regime colonial-capitalístico se instalou na sociedade no final do século $\mathrm{XV}$, adquirindo sua forma mais catastrófica - financeirizada, neoliberal e globaritária - entre os séculos XIX e XX com a internacionalização do capital e, mais precisamente, em 1970 (ROLNIK, 2018). Nesse período (1970), o contexto educacional-curricular debatia o currículo como um aparato social e ficou conhecido como "teorias da correspondência ou da reprodução". Tais teorias traçavam o diálogo das bases econômicas com o campo cultural, social e educacional (LOPES; MACEDO, 2011).

A escola e os currículos se configuram, no contexto colonial-capitalístico, como dispositivos produtores de corpos. Lopes e Macedo (2011, p. 27) afirmam que nesse período os estudos analisavam "[...] a atuação do sistema educativo na preparação dos sujeitos de cada classe social para assumir os papéis que lhes são destinados pelo sistema capitalista”, e seguem:

[...] a escola contribui para a legitimação de determinados conhecimentos e, mais especificamente, dos grupos que os detêm. A elaboração curricular passa a ser pensada como um processo social, preso a determinações de uma sociedade estratificada em classes, uma diferenciação social reproduzida por intermédio do currículo. Ao invés de método, o currículo torna-se um espaço de reprodução simbólica e/ou material (LOPES; MACEDO, 2011, p. 29).

Na década de 90, o regime colonial-capitalístico acirrou-se. Em múltiplas esferas de vidas humanas e institucionais partículas capitalísticas contaminam as forças da existência determinando a marca do intolerável.

No campo curricular, passado o tempo da ditadura militar, marcado pelas teorias tecnicistas, os discursos marxistas ganharam força. Alastraram-se pelo corpo educacional a pedagogia histórico-crítica com Demerval Saviane, a pedagogia crítico social com Libâneo, a pedagogia crítica de Paulo Freire, e os estudos empreendidos por Apple (1979), cuja problemática ressaltava as relações entre sociedade, cultura, educação e capital. Em suma, a preocupação voltava-se para a forma: "[...] como os currículos escolares (re)criam a hegemonia ideológica de determinados grupos dentro da sociedade” (LOPES; MACEDO, 2011, p. 31).

Outros marcos histórico-político-curriculares concernente ao objeto desse estudo foram: a implementação dos Parâmetros Curriculares Nacionais (PCN's), em 1997, documento elaborado pelo Governo Federal para orientar a educação no país estabelecendo os temas 
transversais para cada disciplina; as Diretrizes Curriculares Nacionais (DCN's), em 2013, caracterizadas por serem normativas orientadoras do planejamento curricular das escolas estabelecendo eixos temáticos para o trabalho em equipes. Mais recentemente, em 2018, a Base Nacional Comum Curricular (BNCC), cujo objetivo normativo e obrigatório visa à elaboração e adequação dos currículos nas esferas municipais e estaduais.

$\mathrm{Na}$ esfera micropolítica, neste mesmo período, surgiram inúmeros grupos que levantavam diferentes bandeiras de lutas. Citamos: os movimentos feministas, os movimentos negros, LGBTQI+, os movimentos indígenas, os movimentos dos trabalhadores, o MST, os quais intercalam ações políticas nas esferas macro e micro.

Deleuze e Guattari (2012, p. 99) afirmam, “[...] tudo é político, mas toda política é ao mesmo tempo macropolítica e micropolítica”. Guattari e Rolnik (2011, p. 149, grifo dos autores) complementam a afirmação inferindo que: "[...] uma analítica das formações do desejo no campo social - a questão - diz respeito ao modo como o nível das diferenças sociais mais amplas (que chamei de 'molar') se cruza com aquele que chamei de 'molecular'”.

$\mathrm{Na}$ educação essa relação se entrelaça as práticas-políticas vividas nas escolas. Se “o molecular, como processo, pode nascer no macro. O molar pode se instaurar no micro" (GUATTARI; ROLNIK, 2011, p. 150). Considera-se que há micropolíticas na dimensão do instituído ou nas determinações advindas de um aparelho de Estado e há macropolíticas na dimensão do instituinte ou nas produções que emergem de uma máquina de guerra nômade.

A coexistência de dimensões macro-micropolíticas exige uma prudência (DELEUZE; GUATTARI, 2012) para apreender quais os fluxos desejantes que podem, ou não, estar sendo maquinadas nos entre-acontecimentos das práticas-políticas curriculares. Ou seja, que maquinações desejantes têm movimentado as práticas curriculares?

O desejo é fluxo, é construção, inclusive, das formas-forças que constituem uma máquina curricular social. Nesse viés, pode ou não, gerar um campo de representação e de reprodução de dispositivos que tornam os corpos dóceis (FOUCAULT, 2014).

Os estudos de Oliveira e Fonseca (2006, p. 136) assinalam que, nos cotidianos das escolas, "[...] travam-se lutas permanentes entre processos instituidos e naturalizados, que buscam aprisionar o processo vital através de estratégias de normatização e de formas hegemônicas, e os processos instituintes, as formas de invenção de alteridade”.

Nesse sentido, ao cartografar um cotidiano escolar podemos encontrar modos curriculares que trazem as marcas das prescrições advindas de um aparelho de Estado. No entanto, é possível inventar processos que fogem às normatizações e produzir uma política da diferença e da alteridade.

Revista Interinstitucional Artes de Educar. Rio de Janeiro, V.7, N.3 - pág. 1650-1665 set-dez de 2021: "Dossiê Relatos de experiências e produção acadêmica” - DOI: https://doi.org/10.12957/riae.2021.54802 
À vista disso, para produzir uma política da diferença comprometida com a produção de corpos e subjetividades ativas, pensamos ser necessário uma prudência no modo como as máquinas desejantes são operadas, pois somos constituídos por um corpo social segmentarizado por linhas molares e moleculares.

Frente às linhas catastróficas do regime colonial-capitalístico (ROLNIK, 2018) e mediante as relações micro-macropolíticas que afetam o campo educacional, indicamos os caminhos que pretendemos construir para uma vida não fascista. Que entre o nó da garganta que nos afeta e o respiro prudente tão necessário para atravessar essa atmosfera tóxica, possamos fazer passar-vazar o desejo vital da criação de outros modos de vida.

$\mathrm{Na}$ defesa de uma arte da resistência inventada com os cotidianos, assumimos o conceito menor (DELEUZE; GUATTARI, 2017) para pensar nas produções curriculares tecidas com as escolas. Com Ferraço (2016, p. 242), entendemos os currículos como múltiplos fazeres-saberes que acontecem com os cotidianos das escolas em suas relações micro-macropolíticas. Compreendemos com o autor (2016):

[...] sabemos que, independente de haver ou não uma proposta comum de ação, as redes continuam a ser tecidas pelos sujeitos das escolas, o que nos leva a pensar que o que importa nesses processos instituintes não é a existência ou não de um projeto prescritivo, mas o sentimento comum de que trabalhamos e atuamos sempre em redes e de que qualquer tentativa de se constituir como protagonista individual e autocentrado na produção do currículo não nos leva muito longe na educação. A força sempre estará no coletivo e nas redes tecidas nos cotidianos das escolas.

Empreendemos pensar como os currículos praticados com os cotidianos escolares podem contribuir com uma vida não fascista diante dos agenciamentos da máquina capitalística. De antemão, ressaltamos: o fascismo é, também, uma máquina desejante.

Deleuze e Guattari (2012) inferem que o fascismo atravessa as segmentaridades molares, no âmbito da macropolítica, e as segmentaridades moleculares, no âmbito da micropolítica. Neste tempo pandêmico e catastrófico, refletimos: "é muito fácil ser antifascista no nível molar, sem ver o fascista que nós mesmos somos, que entretemos e nutrimos, que estimamos com moléculas pessoais e coletivas” (DELEUZE; GUATTARI, 2012, p. 102).

Imersa em um tempo cujas forças vitais são expropriadas por um complexo de maquinações - fascismo, capitalismo, queimadas, extermínios, conservadorismo, neoliberalismo, negacionismo - com Rolnik (2018), problematizamos o abuso da vida que, segundo a autora, acontece por modos de cafetinagem, ou seja, por intermédio das múltiplas formas como o capital se apropria da vida.

[...] é da própria vida que o capital se apropria; mais precisamente, de sua potência de criação e transformação em seu nascedouro - ou seja, sua essência germinativa -, bem como da cooperação da qual tal potência depende para que se efetue em sua 
singularidade. A força vital de criação e cooperação é assim canalizada pelo regime para que construa um mundo segundo seus desígnios. Em outras palavras, em sua nova versão é a própria pulsão de criação individua e coletiva de novas formas de existência, suas funções, seus códigos e suas representações que o capital explora, fazendo dela seu motor. Disto decorre que a fonte da qual o regime extrai sua força não é mais apenas econômica, mas também intrínseca e indissociavelmente cultural e subjetiva - para não dizer ontológica -, o que lhe confere um poder perverso mais amplo, mais sutil e mais difícil de combater (ROLNIK, 2018, p. 32-33).

As maquinações do abuso vital agem nos corpos de forma a configurar linhas segmentarizadas, molar-moleculares, cujo desafio é a insurgência de ações que façam-vazar o desejo por uma resistência micropolítica ativa. Concernente aos modos de aprisionamento dos corpos, percebemos ações de controle e disciplinamento sendo efetuadas por meio, por exemplo, das prescrições curriculares ao ditarem o lugar dos corpos nas escolas.

Em entrevista publicada pela revista Re-visiones, Suely Rolnik chama a atenção: “[...] é preciso deslocar-se da micropolítica dominante, a qual abarca a própria esquerda. Refirome a micropolítica reativa do inconsciente colonial-capitalístico que comanda o sujeito moderno" (ROLNIK, 2016, np). Assim, é preciso romper com os documentos normativos escolar-curriculares que agem em prol das políticas dominantes, seja de modo micropolítico, seja macropolítico.

A micropolítica reativa, que abordaremos mais adiante com mais densidade, vincula-se aos modos representacionais e é orientada pelo que a autora chama de perspectiva antropo-faloego-logocêntrica. Rolnik (2018, p. 91, grito da autora) define: "Qualifico de 'antropo-falo-egologocêntrica' essa política reativa de produção do pensamento, regida pelo inconsciente colonial-capitalísitico".

A perspectiva antropo-falo-ego-logocêntrica atua na inibição da potência criadora do vivente e conserva o status quo na perpetuação e manutenção do controle e dos modos de regulação. Nesse sentido,

[...] a ordem capitalística produz modos das relações humanas até em suas representações inconscientes: os modos como se trabalha, como se é ensinado, como se ama, como se transa, como se fala, e não para por aí. Ela fabrica a relação com a produção, com a natureza, com o presente, com o passado e com o futuro - em suma, ela fabrica a relação do homem com o mundo e consigo mesmo. Aceitamos tudo isso porque partimos do pressuposto de que esta é ' $a$ ' ordem do mundo, ordem que não pode ser tocada sem que se comprometa a própria ideia de vida social organizada (GUATTARI; ROLNIK, 2011, p. 51, grifo dos autores).

Percebemos a perspectiva antropo-falo-ego-logocêntrica no modo como os corpos são apropriados nas escolas. Uma captura regida por documentos curriculares que controlam, disciplinam e inibem a produção da diferença. Corpos maquinados pelos currículos 
prescritivos-normativos, robotizados e, portanto, podendo estarem inertes a uma prática criadora.

Ao delinear sobre micropolíticas, Rolnik (2016; 2018), propõe a tessitura de outros modos de vida possíveis. Uma vida cujo desejo esteja no âmbito do fazer coletivo e da arte como pulsão criadora. Por isso, temos apostado em uma arte da resistência como linhas de fuga ao modo como a existência tem sido expropriada da sua pulsão vital.

Destarte, "o desejo é então convocado a agir a fim de recobrar um equilíbrio vital. Esta é uma experiência inevitável, pois resulta da própria demanda da vida em sua essência de processo contínuo de transformação” (ROLNIK, 2016, np).

Assim, os corpos são máquinas produtoras de uma vida cujos desejos são construções que germinam das relações dos corpos com o mundo, inclusive, com as relações estabelecidas com os cotidianos escolares por meio da maquinaria curricular. Deleuze e Guattari (2011, p. 43) inferem:

Se o desejo produz, ele produz real. Se o desejo é produtor, ele só pode sê-lo na realidade, e de realidade. O desejo é esse conjunto de sínteses passivas que maquinam os objetos parciais, os fluxos e os corpos, e que funcionam como unidades de produção. $\mathrm{O}$ real decorre disso, é o resultado das sínteses passivas do desejo como autoprodução do inconsciente. Nada falta ao desejo, não lhe falta sujeito fixo; só há sujeito fixo pela repressão. O desejo e seu objeto constituem uma só e mesma coisa: a máquina, enquanto máquina de máquina. O desejo é máquina, o objeto do desejo é também conectada, de modo que o produto é extraído do produzir e algo se destaca do produzir passando ao produto e dando um resto ao sujeito nômade e vagabundo.

Romper com o controle da máquina capitalista parece ser uma linha de fuga possível para pensar uma vida com a diferença e menos fascista. Eis um desejo: uma vida vinculada à dimensão ética-estética-educacional-política do coletivo, da criação, dos rizomas, da arte, inventadas nos espaços-tempos escolares, onde os corpos estão sob o julgo de ser docilizados (FOUCAULT, 2014). No campo da educação, suspeitamos que uma ação curricular menor pode devir uma arte da resistência. Segundo Rolnik (2018, p. 33, grifo da autora):

[...] a resistência hoje passaria por um esforço de reapropriação coletiva dessa potência para com ela construir o que tais autores chamam de 'o comum' [...] o campo imanente da pulsão vital de um corpo social quando a toma em suas mãos, de modo a direcioná-la à criação de modos de existência para aquilo que pede passagem.

Entendemos: "A noção de comum é algo que justamente diz a potência dos corpos encontrantes e da relação característica do corpo formado no encontro" (YONEZAWA; CARDOSO JÚNIOR, 2016, p. 180). A ideia de comum é, nesse sentido, fluxo de passagem, encontro de corpos, uma rede entrelaçada de afetos potentes que pode liberar a vida do aprisionamento das macropolíticas. 
Nesse sentido, o comum não se refere a uma igualdade ou à efetivação de um processo de ensinar-aprender democrático que dê aos praticantes escolares a possibilidade de um processo educacional rostificado, mas, sobretudo, à ideia de uma criação vital que ocorre no momento das aprendizagens.

Dessa maneira, se temos uma produção curricular produzida entre as linhas molares e moleculares, ou seja, na fronteira entre o aparelho de Estado e a máquina de guerra nômade, é preciso pensar nas linhas de fuga traçadas pelos corpos que escapam dos regimes segmentarizados e que, nesse mesmo processo, possibilitam a produção de um tipo de resistência coletiva no plano da imanência escolar.

Assim, questionamos: que maquinações desejantes agenciam, por exemplo, a implementação de uma Base Nacional Comum Curricular? E ainda, que engrenagens produzem os agenciamentos dos múltiplos fazeres-saberes tecidos com os cotidianos escolares?

As práticas curriculares devem nutrir o desejo micropolítico ativo apontando outros horizontes políticos democráticos e colocar em suspensão os modos de produção da máquina capitalística. O que devemos almejar é traçar outras linhas para a afirmação da vida. Para que isso aconteça, é necessário questionar como o capital tem enclausurado as formas-forças da produção da subjetividade, da corporeidade, dos corpos e da diferença.

Diante do exposto e de uma realidade brasileira que retoma políticas colonizadoras, conservadoras e neoliberais e, por isso, expropriam a vida da sua potência criadora, pensar nos fluxos e devires que acontecem com os cotidianos das escolas pode ser um caminho possível para outros horizontes de vida coletiva, visto que "o cotidiano da escola, esse campo de acontecimentos, é um espaço em que vemos manifestarem-se as diferenças” (GALLO, 2007, p. 32) e ainda, "abrir-se para as relações do cotidiano da escola, mergulhar nesses acontecimentos, agindo nesse cotidiano como vetor de transformação é possibilidade de resistir à exclusão e investir na construção da cidadania” (GALLO, 2007, p. 38).

Como já foi apontado, acreditamos que uma micropolítica ativa está afeta as práticaspolíticas curriculares menores produzidas com os cotidianos escolares, visto serem “[...] aberturas e horizontes, espécie de deserto em que os fluxos correm soltos e as diferenças aparecem" (GALLO, 2007, p. 38). Nesse viés, problematizar a maquinaria curricular é fazervazar uma possibilidade de romper com determinações hegemônicas que servem ao abuso profanador da vida.

Se tratando de estudos educacionais e curriculares, cartografar os cotidianos escolares tendo como protagonista quem habita as escolas pode ser, também, um fluxo possível na transição de um pensamento reativo para o pensamento ativo. Essa é a nossa aposta. 
Ao pensar em um outro modo de vida, propomos diagnosticar as produções de subjetividades e as configurações das máquinas desejantes. Concordamos com Rolnik (2018, p. 36):

Insurgir-se nesse terreno implica que se diagnostique o modo de subjetivação vigente e o regime de inconsciente que lhe é próprio, e que se investigue como e por onde se viabiliza um deslocamento qualitativo do princípio que o rege. Sem isso, a tão propalada reapropriação coletiva da força criadora como profilaxia para a patologia do presente não sairá do laboratório das ideias, correndo o risco de permanecer confinada no plano imaginário e suas belas ilusões alentadoras.

Decerto, estamos arregimentados por um inconsciente colonial-capitalístico que produz o abuso da vida e os saberes-poderes que constitui as formas-forças que controlam e disciplinam uma vida. A esse modo de produção, optamos por chamá-lo no decorrer do texto, assim como Rolnik (2018), por inconsciente colonial-cafetinístico.

Retomando o diálogo educacional-curricular, outra questão que propomos é: como os currículos praticados com os cotidianos das escolas pode subverter essa maquinação capitalística apontando novas linhas-forças para um outro modo de vida possível?

Outra problemática a ser pensada é concernente à produção de subjetividades o que requer o ato de violentar o pensamento e inventar, ações que ocorrem de modo inseparável e coletivo, e que almejamos tecer para pensar nos deslocamentos curriculares.

Suspeitamos, pensar os currículos praticados com as escolas necessita da efetuação de um corte nas políticas que legitimam os fazeres-saberes, um corte não estéril. Imersa nas configurações da sociedade do controle, o risco do corte estéril na manutenção do inconsciente colonial-cafetinístico é real, devido à capacidade "pessoal-sensorial-sentimental-cognitiva" com a qual os corpos apreendem o mundo e constituem a sua subjetividade.

Decerto há um modo de curricular nas escolas que são construídas por experiências molares, por linhas segmentarizadas e estratificadas pelo aparelho de Estado cujo objetivo pauta-se na reprodução, na representação e na configuração de uma rostidade. A Base Nacional Comum Curricular (BNCC), por exemplo, na prática discursiva do comum induz a uma ação micropolítica democrática - compete dizer, uma micropolítica cafetinada e reativa - cujo princípio igualitário esteriliza a produção da diferença em uma corporeidade que se quer múltipla e diferenciada.

O contexto da produção dessa prescrição normativa - BNCC - está associada ao "seriado do Golpe", ou seja, aos processos de usurpação da vida pelo capital financeirizado, neoliberal e neoconservador proposto nos estudos de Rolnik (2018). A maquinação da produção 
de subjetividades perpassa por ações cafetinas e de roubo dos corpos cuja força motriz está nas relações de gênero e sexualidade negadas no texto curricular.

No campo da educação, durante as discussões no congresso em torno da nova Base Nacional Comum Curricular (BNCC) demoniza-se nos currículos escolares qualquer abordagem de temas ligados à política (o famoso lema 'Escola sem partido'), à identidade de gênero, à orientação sexual e às culturas africanas e indígenas. Aprovada em 2017, na nova BNCC foram eliminados trechos que afirmavam a necessidade de um ensino sem preconceitos. Mais especificamente, foram excluídos mais de dez trechos que mencionavam as questões de gênero e sexualidade e eliminados da bibliografia textos que abordassem a mitologia dos orixás, com o argumento de que seu conteúdo seria demoníaco. Tais cortes do currículo escolar têm seu lastro nas operações micropolíticas mencionadas nos dois exemplos anteriores (LGBTQI, afrodescendentes e indígenas) e participam da construção da mesma narrativa do seriado que agora tem nessas camadas da sociedade um novo personagem para seu núcleo de vilões (ROLNIK, 2018, p. 171).

À medida que o surto conservador (ROLNIK, 2018) se instala no âmbito macropolítico por meio de narrativas que invocam os padrões heteronormativos, a BNCC age em uma produção que entrelaça macro-micropolíticas. A base nacional comum reforça o poder dominante ao anular as diferenças e, essa é justamente uma produção micropolítica da cafetinagem, pois reforça preconceitos, exclusões e a produção de uma rostidade ao determinar que corpos precisam ser combatidos veementemente para a construção de uma nação soberanamente heteronormativa.

O resultado das práticas curriculares segmentarizadas pelas linhas molares pode contribuir para as configurações de uma subjetividade limitada as experiências "pessoalsensorial-sentimental-cognitiva". Rolnik (2018, p. 52) explica:

É que na política de subjetivação dominante nesses contextos tendemos a nos restringir à experiência enquanto sujeitos e a desconhecer que se esta é sem dúvida indispensável - por viabilizar a gestão do cotidiano, a sociabilidade e a comunicação -, ela não é a única a conduzir nossa existência; várias outras vias de apreensão de um mundo operam simultaneamente.

A pergunta que segue é necessária na violentação do pensamento que norteia esse estudo: estamos dispostos a tecer uma vida coletiva e a produzir o comum vislumbrando uma vida não cafetinada e, no atual contexto político brasileiro, uma vida não fascista?

Para aventurar-se nas linhas de fuga, rompendo com o que aprisiona os corpos e produzindo uma máquina de guerra nômade, é necessário: a) pensar com a ideia de corpo-semórgãos nos estudos dos currículos, ou seja, a provocação de uma desorganização do corpo normativo; b) maquinar o exercício da desobediência; e, c) experimentar o mundo por meio dos perceptos e afectos. Criar para si um corpo-sem-órgãos, desobedecer e experimentar pelos perceptos e afectos diz respeito, por tanto, a uma pulsão vital e criadora dos corpos em processos de artesania. 
O corpo-sem-órgãos diz respeita ao modo como podemos romper com as organizações e inventar processos curriculares que façam alianças com as artesanias. Desobedecer refere-se aos processos de fuga de um sistema que aprisiona e disciplina os corpos, o inibindo de sua produção da diferença. Para experimentar o mundo por meio dos perceptos e afectos, devemos entender que os "perceptos e afectos não tem imagem, nem palavra, nem gesto que lhes correspondam - enfim, nada os expresse - e, no entanto, são reais, pois dizem respeito ao vivo em nós mesmos e fora de nós" (ROLNIK, 2018, p. 53).

Criar um corpo-sem-órgãos, desobedecer e experimentar o mundo por perceptos e afectos refere-se a traçar maquinações desejantes que produzem subjetividades e se veem na dualidade das forças de conservação do status quo ou na subversão germinadora de outros fluxos de vida. Nesse viés, pensar um corpo e uma arte da resistência entre as forças reativas e ativas se faz necessário.

\section{Maquinações III: um corpo e uma arte da resistência entre as forças reativas e ativas}

Ao longo do texto temos dito sobre uma micropolítica reativa e uma micropolítica ativa pela relação que é estabelecida com os corpos. Assim sendo, Deleuze (2018, p. 56) infere: “o que define um corpo é a relação entre forças dominantes e forças dominadas. Toda relação de formas constitui um corpo: químico, biológico, social, político”.

Concordando com Deleuze (2018, p. 57), inferimos que os corpos são múltiplos e constituídos por uma diversidade de forças, ora força ativa, ora força reativa. As forças reativas "[...] nada perdem de sua força, de sua quantidade de força, elas a exercem assegurando os mecanismos e as finalidades, cumprindo as condições de vida e as funções, as tarefas de conservação, de adaptação e de utilidade".

Quanto às forças ativas, o autor (2018), acrescenta: "apropriar-se, apoderar-se, subjulgar, dominar são as características da força ativa. Apropriar-se quer dizer impor formas, criar formas explorando as circunstâncias" (DELEUZE, 2018, p. 58).

A micropolítica ativa tem a ver com uma política do desejo. Para isso, é preciso produzir um corte ativo, ou seja, traçar rizomas e fazer vazar uma multiplicidade de corpos. Tratando-se de currículos, o corte pode ser realizado sempre em uma das superfícies topológico-relacional arregimentadas pelo aparelho de Estado e efetuadas pelos encontros criados com os praticantes das escolas.

Rolnik (2018, p. 61) afirma: "nessa micropolítica, as ações do desejo consistem, portanto, em atos de criação que se inscrevem nos territórios existenciais estabelecidos e suas respectivas cartografias, rompendo a cena pacata do instituído”. A ressonância dessa 
micropolítica ativa pode disparar uma ética da existência que assumimos nessa pesquisa em educação. Assim, "Regido por essa micropolitica, o desejo cumpre sua função ética de agente vivo da criação de mundos, próprio de uma subjetividade que busca colocar-se à altura do que lhe acontece" (ROLNIK, 2018, p. 65).

As práticas curriculares tecidas com os cotidianos das escolas podem, ou não, atingir a força de uma micropolítica ativa ao efetuar cortes e produzir linhas de fuga vinculadas a uma ética da diferença. A micropolítica reativa refere-se ao corte efetuado sempre no mesmo ponto da esfera topológico-relacional. Um corte realizado, por exemplo, no mesmo ponto dos documentos prescritivos e, considerando as ações cotidianas como invenções sem problematizá-las, como processos que também podem ou não, ser representações.

Contudo, Rolnik (2018, p. 184) alerta:

Ninguém é permanentemente ativo ou reativo, tais posições oscilam e se mesclam ao longo da existência individual e coletiva. O que importa do lado das forças ativas é o trabalho incansável que consiste em combater as forças reativas em nós mesmos e em nosso entorno, cujo sucesso jamais estará garantido e tampouco será definitivo.

Ao campo dos estudos em questão, compete problematizar as maquinações desejantes efetuadas sobre o espaço topológico-relacional da produção de subjetividades atreladas aos dispositivos curriculares. Pensar as escolas como esse campo de formas-forças que são maquinadas pelas bússolas ética e moral e delas apreender até que ponto subvertemos a ordem instituída pelo aparelho de Estado configurando, portanto, uma máquina de guerra nômade, ou se estamos a produzir um constante estado de representações.

Nesse estudo, o que interessa é estarmos atenta ao lugar da imanência dos corpos, isso devido a redução da subjetividade ao sujeito e ao condicionamento do plano de imanência ao campo transcendental-representacional.

É que da perspectiva dessa política de desejo, diferente das visões de mundo passam a equivaler-se, já que a relação que a subjetividade estabelece com qualquer uma delas é a mesma: seu consumo para recobrar temporariamente uma voz por meio do mero eco. Seja qual for a visão adotada, ela é usada como um discurso-clichê que serve de guia para uma subjetividade que, dissociada de sua condição de vivente, não tem como encontrar palavras para o que the acontece (ROLNIK, 2018, p. 73).

Insistimos no campo da produção das subjetividades e dos corpos por considerar que nas escolas, por meio das práticas normativa-curriculares são delineadas desejos e produzidos corpos e subjetividades orientadas por micropolíticas ativas e reativas. O perigo, do qual estamos a colher alguns frutos é, justamente, a produção dos corpos fascistas. Nessa perspectiva, o risco é: 
[...] a diminuição da potência da condição de vivente, produzindo uma espécie de anemia vital, mas nem por isso menos presente e poderosa em seus efeitos. [...] a eterna reprodução das formas do mundo em sua atual configuração. constataremos que o que se debilita é precisamente a potência coletiva da criação e cooperação, condição para a construção do comum, a qual emana do poder de insurgir-se e, ao mesmo tempo, o fortalece (ROLNIK, 2018, p. 75).

Estar atento aos modos como traçamos-apreendemos as linhas micropolíticas no campo dos fazeres-saberes curriculares é de extrema importância nas cartografias escolares. As aprendizagens são revestidas de potencialidades por acontecerem com os corpos em sua força de afetar e ser afetados, e estarem inseridas no contexto das máquinas capitalísticas que, com o passar do tempo, refinam suas formas de abusar da vida.

Uma das modalidades refinadas do abuso da vida no regime financeirizado ocorre de forma midiática. Os dispositivos tecnológicos e suas engrenagens permitem o acesso às informações com uma velocidade absurda e possibilita o contorno que se quer dar aos corpos.

No Brasil, assistimos desde 2016 o refinamento desse abuso no setor político. O começo dos seriados do golpe ocorreu com as maquinações que ascendeu a destituição do cargo da presidenta Dilma marcando, portanto, o golpe à democracia, e culminando com a ascensão ao poder de um governo autoritário, a "era” Bolsonaro. Rolnik (2018, p. 161) aponta esse avanço:

[...] as novas tecnologias de comunicação permitiram um aprimoramento significativo desse dispositivo de poder: a sofisticação das linguagens e das técnicas de manipulação e publicidade (produzindo uma profunda mudança na televisão), a multiplicação de mídias e o alcance mundial da disseminação das mensagens em tempo real.

A Educação sofreu um estupro de sua potência de vida com a engrenagem do dispositivo tecnológico. As narrativas impulsionadas por robôs noticiavam que nas escolas haviam sido entregues, pelos partidos dos trabalhadores, materiais de conotação sexual. A repetição dos discursos produziu uma noção de verdade em uma sociedade contagiada pelo conservadorismo, a qual alavancou a efetivação do governo atual.

A listagem dos ataques à educação e à produção de regimes de verdade por parte do governo é extensa: fake news sobre a existência de kits gays nas escolas; ataque aos cursos de ciências humanas; cortes no orçamento das universidades federais; corte orçamentário no setor da educação; cortes e bloqueio na bolsa Capes; Mec priorizando o Ensino Superior privado; o presidente chamando os estudantes de "idiotas úteis"; a autorização para a presença da polícia nas universidades com objetivo de coibir o viés ideológico propagado, etc.

Essas são algumas das ações de cafetinagem executadas pela macropolítica para despotencializar a Educação da sua pulsão vital. Rolnik (2018, p. 172) explica o objetivo micropolítico dos ataques à educação. Segundo a autora, é: 
[...] enfraquecer o acesso à informação e à formação intelectual na sociedade brasileira como um todo, o que tem por efeito debilitar a potência do pensamento, essencial para decifrar as asfixias da vida em suas formas presentes e combate-las, criando novos cenários.

Diante desse cenário complexo no qual nos encontramos como corpos coletivos, e na incessante produção de subjetividades tecidas entre as linhas micro-macropolíticas, a insurgência é necessária em todos os âmbitos cujas relações com o aparelho de Estado acontecem.

Pensar a educação e os entrelaçamentos maquínicos curriculares se tornam, nesse contexto, uma produção de linha de fuga aos processos que enrijecem os corpos e os introduzem nos moldes do capitalismo financeirizado em sua forma mais perversa. Traçar-criar outros modos de subversões e resistências é um exercício ético-político. Respirar é urgente. Devirarteiro é uma insurgência.

[...] é preciso também tomar para si a responsabilidade como ser vivo e lutar pela reapropriação das potências de criação e cooperação e pela construção do comum que dela depende. Em outras palavras, não basta um combate pelo poder macropolítico e contra aqueles que o detêm, há que se levar igualmente um combate pela potência afirmativa de uma micropolítica ativa, a ser investida em casa uma de nossas ações cotidianas - inclusive naquelas que implicam nossa relação com o Estado, que estejamos dentro ou fora dele (ROLNIK, 2018, p, 89).

Nesse sentido, em vias de inconclusões, consideramos que uma arte da resistência passa pela criação de uma experimentação corpo-sem-órgãos visto ser uma artesania vital. Uma experimentação que não tem roteiro preestabelecido, mas que deve fazer uma aliança com a arte. Deleuze e Guattari (2011, p. 34) afirmam:

O corpo sem órgãos é um ovo: é atravessado por eixos e limiares, por latitudes, longitudes e geodésias, é atravessado por gradientes que marcam os devires e as passagens, as destinações daquele que aí se desenvolve. Nada é aqui representativo, tudo é vida e vivido: a emoção vivida dos seios não se assemelha aos seios, não os representa, assim como uma zona predestinada do ovo não se assemelha ao órgão que será induzido nela; apenas faixa de intensidade, potenciais, limiares e gradientes. Experiência dilacerante, demasiado emocionante, pelo qual o esquizo é aquele que mais se aproxima da matéria: 'emoção situada fora do ponto particular em que o espírito a busca... a emoção que dá ao espírito o som sublevador da matéria, para onde toda a alma escorre e arde'.

Assim, uma arte da resistência é afeta aos processos de experimentações que criam uma outra possibilidade ética-estética-política com a vida. Levy (2011 p. 137) afirma: "Resistir é devir-outro, é despertar o outro que existe em nós mesmos, como o impensado que existe no pensamento. Resistir é tornar-se estrangeiro, estranho na própria cultura, é devir menor, tornar-se nômade, exilado, errante”.

Portanto, pensar e desejar uma arte da resistência com os cotidianos escolares que faça aflorar outros gérmens de mundo (ROLNIK, 2018) e, nesse sentido, produzir outras forças Revista Interinstitucional Artes de Educar. Rio de Janeiro, V.7, N.3 - pág. 1650-1665 set-dez de 2021: "Dossiê Relatos de experiências e produção acadêmica" - DOI: https://doi.org/10.12957/riae.2021.54802 
coletivas de resistência tem a ver com práticas-políticas menores, com o entrelaçamento de fazeres-saberes afetos ao que pulsa nas escolas como maquinações menores de uma vida e, só faz sentindo pensar nessa perspectiva, se assumimos a artesania como força ativa, como um gesto de educar.

\section{Referências}

BRASIL. Ministério da Educação. Parâmetros Curriculares Nacionais. Bases Legais. Brasília, 1997.

BRASIL. Ministério da Educação. Diretrizes Curriculares Nacionais para a Educação Básica. Brasília, 2013.

BRASIL. Ministério da Educação. Base Nacional Comum Curricular. Brasília, 2018.

DELEUZE, Gilles. Conversações. São Paulo: Editora 34, 2013.

DELEUZE, Gilles. Crítica e clínica. São Paulo: Editora 34, 2011.

DELEUZE, Gilles. Nietzsche e a filosofia. São Paulo: n-1 edições, 2018.

DELEUZE, Gilles; GUATTARI, Félix. Kafka: por uma literatura menor. Belo Horizonte: Autêntica Editora, 2017.

DELEUZE, Gilles; GUATTARI, Félix. Mil platôs: capitalismo e esquizofrenia 2. São Paulo: Editora 34, 2012.

DELEUZE, Gilles; GUATTARI, Félix. O anti-Édipo: capitalismo e esquizofrenia 1. São Paulo: Editora 34, 2011.

DELEUZE, Gilles; GUATTARI, Félix. O que é a filosofia? São Paulo: Editora 34, 2010.

FERRAÇO, Carlos Eduardo. ...e currículos. In: FERRAÇO, C.E. (orgs.). ...Currículos em redes. Curitiba: CRV. 2016.

FOUCAULT, Michel. Vigiar e punir: nascimento da prisão. 42. ed. Petrópolis, RJ: Vozes, 2014.

GALLO, Silvio. Acontecimento e resistência: educação menor no cotidiano da escola. In: CAMARGO, Ana Maria Faccioli. de; MARIGUELA, Márcio (orgs.). Cotidiano escolar: emergência e invenção. Piracicaba: Jacintha Editores, 2007.

LAWRENCE, David Herbert. Caos em poesia. Florianópolis: Cultura e Barbárie, 2016.

LEVY, Tatiana Salem. A experiência do fora: Blanchot, Foucault e Deleuze. Rio de Janeiro: Civilização Brasileira, 2011.

LOPES, Alice Casimiro; MACEDO, Elisabeth. Teorias de currículo. São Paulo: Cortez, 2011.

OLIVEIRA, Andréia Machado; FONSECA, Tania Mara Galli. Os devires do territórioescola: trajetos, agenciamentos e suas paisagens. Educação \& Realidade. Rio Grande do Sul, v. 31, n. 2, p. 135- 154, 2006. Disponível em:

http://seer.ufrgs.br/educacaoerealidade/article/viewFile/6849/4120. Acesso em: 26 jun. 2020

ROLNIK, Suely. Esferas da insurreição: notas para uma vida não cafetinada. São Paulo. n-1 edições, 2018. 
ROLNIK, Suely. Una conversación com Suely Rolnik (Universidad católica de São Paulo), por Aurora Fernández Polanco/ Antonio Pradel. In: Re: visiones - Revista de arte y pensamento visual contemporáneo da Univesidad Complutense de Madrid (bilíngue espanhol/inglês), 2016. Disponível em: http://www.re-visiones.net/. Acesso em: 26 jun. 2020 YONEZAWA, Fernando.; CARDOSO JÚNIOR, Hélio Rebello. Deleuze e Spinoza e a vigência do corpo-aprendiz: sensibilidade e educação. In: BRITO, Maria dos Remédios de.; GALLO, Silvio. (orgs.). Filosofias da diferença e educação. São Paulo: Editora Livraria da Física, 2016. 